\section{Post liposuction \\ Mycobacterium abscessus surgical site infection in a returned medical tourist complicated by a paradoxical reaction during treatment}

\author{
Siong H. Hui,' Lisa Noonan, ${ }^{2}$ \\ Ruchir Chavada ${ }^{3}$ \\ 'Department of Infectious Diseases, \\ Fiona Stanley Hospital; ${ }^{2}$ Department of \\ Microbiology and Infectious Diseases, \\ Sydney South West Pathology Services, \\ Liverpool Hospital; ${ }^{3}$ Department of \\ Microbiology and Infectious Diseases, \\ Pathology North Gosford Hospital, \\ Australia
}

\section{Abstract}

Rapidly growing mycobacterial skin and soft tissue infections are known to complicate cosmetic surgical procedures. Treatment consists of more surgery and prolonged antibiotic therapy guided by drug susceptibility testing. Paradoxical reactions occurring during antibiotic therapy can further complicate treatment of non-tuberculous mycobacterial infections. We report a case of post liposuction Mycobacterium abscessus surgical site infection in a returned medical tourist and occurrence of paradox during treatment.

\section{Case Report}

A 41-year-old Vietnamese-born, nonimmunocompromized woman presented in April 2012 with a one month history of painful nodules and discharging sinuses on her neck, upper arms, right thigh and across her lower abdomen (Figure 1A). She had been dissatisfied with the residual surgical scars which resulted from an abdominoplasty performed in Sydney, Australia in 2008. Consequently, during a trip to Vietnam, she consulted a cosmetic specialist, who performed liposuction and scar excision on her neck, upper arms, lower abdomen and thighs. She was taking venlafaxine for depression.

Clinical and radiological evaluation revealed subcutaneous abscesses and cavities on her right thigh, lower abdominal wall, upper arms and anterior neck. Swabs of pus from abscesses failed to isolate any bacteria on routine culture. The lesions persisted despite the empiric use of flucloxacillin and subsequently piperacillin-tazobactam over 2 weeks.
Following an infectious diseases consultation rapidly-growing mycobacteria, nocardia species and fungi were considered as potential causes. HIV antibody testing was negative.

Acid-fast bacilli (AFB) were detected on microscopy of debrided tissue. Growth of mycobacterial colonies occurred within 5 days, which were subsequently identified as Mycobacterium abscessus subsp abscessus by 16s rRNA polymerase chain reaction (PCR). Susceptibility testing by Etest (ABbiodisk, Solna, Sweden) suggested in vitro susceptibility to amikacin and clarithromycin, intermediate susceptibility to imipenem, cefoxitin and linezolid and resistance to the fluoroquinolones, trimethoprim-sulfamethoxazole and doxycycline. Treatment was initiated in early May 2012 with intravenous amikacin 750 mg daily, intravenous cefoxitin infusion $12 \mathrm{~g}$ daily and oral clarithromycin $500 \mathrm{mg}$ twice a day. The intention was for the parenteral agents to be given for 6 weeks with clarithromycin followed by at least 6-12 months of clarithromycin.

Within 3 weeks of commencing antimicrobial treatment, new nodules developed in her upper abdomen, right thigh and left leg (Figure 1B). Debrided tissue samples revealed no AFB on microscopy but M.abscessus continued to be isolated, indicating need for further source control surgery. Her treatment was complicated by a series of adverse drug reactions. The first was a generalized maculopapular rash (Figure 1B), for which cefoxitin was implicated by process of elimination. Treatment was reinstituted in late June 2012 with oral linezolid $600 \mathrm{mg}$ twice a day in combination with amikacin and clarithromycin. Venlafaxine was discontinued in view of a potential interaction with linezolid (serotonin syndrome) and her usual psychiatrist was involved in her care.

The abscesses reappeared on her abdomen, thighs and left elbow in mid July 2012. However, debrided tissue no longer isolated the organism. The second adverse drug reaction occurred two weeks later when linezolid was discontinued due to pancytopenia and deranged liver function tests. Amikacin was also ceased at this time after 6-weeks uncomplicated by adverse events attributable to aminoglycoside use. With no other antibiotic options, clarithromycin was continued as monotherapy.

The recurrence of abdominal, thigh and arm abscesses in late August 2012 raised the concern for evolving resistance to clarithromycin (erm gene). However, further operative tissue specimens failed to demonstrate any growth of M. Abscessus. The possibility of a paradoxical reaction to anti-mycobacterial treatment was considered. A 2-week course of prednisone at a dose of $25 \mathrm{mg}$ daily was instituted with almost complete resolution of lesions. Cessation was
Correspondence: Ruchir Chavada, Department of Microbiology and Infectious Diseases, Gosford Hospital, Holden St, Gosford NSW 2250, Australia. Tel.: +61.02.4320.2432 - Fax: +61.02.4320.3657. E-mail: ruchirchavda@gmail.com

Key words: Mycobacterium abscessus; cosmetic surgical procedures; surgical site infections; medical tourism.

Contributions: SH, managed the patient, drafted first version of manuscript and literature review; $\mathrm{RC}$, literature review, critical review of the manuscript; LN, managed the patient and critical review of manuscript.

Conflict of interest: the authors declare no potential conflict of interest.

Received for publication: 11 November 2015 . Revision received: 23 November 2015.

Accepted for publication: 2 December 2015.

This work is licensed under a Creative Commons Attribution NonCommercial 3.0 License (CC BYNC 3.0).

(C) Copyright S.H. Hui et al., 2015

Licensee PAGEPress, Italy

Infectious Disease Reports 2015; 7:6304

doi:10.4081/idr.2015.6304

followed by recurrence of the paradoxical reaction and prednisone was resumed with a view to a longer course, with good effect. However, the steroid treatment was complicated by acne, alopecia, weight gain and cushingoid facial features after 2 months. Consequently, prednisone was tapered by $1 \mathrm{mg}$ per week until its complete discontinuation in mid-December 2012. Small nodules recurred on her lower abdomen in January 2013 and on her right thigh in May 2013 but these were small and transient. No further nodules (paradoxical reaction) or abscesses had since recurred and she completed an 18 month course of clarithromycin with full resolution of the infection. There has been no evidence of relapse in her RGM infection to date.

\section{Discussion}

This case illustrates that the differential diagnosis of a surgical site infection in a returned medical tourist should include RGM such as M. abscessus as a potential cause and outlines the complexity of treatment. It also reports the occurrence of a paradoxical reaction occurring during antimicrobial therapy for $M$. abscessus infection which has been more often recognized as occurring with $M$. tuberculosis treatment.

Non-tuberculous mycobacteria (NTM) are 
present in the environment, with tap water forming an important reservoir, and have been traditionally classified as rapid, intermediate or slow growers based on Runyon's system. ${ }^{1}$ Organisms categorized as RGM include $M$. abscessus, Mycobacterium chelonae and Mycobacterium fortuitum. Most rapidly-growing mycobacteria (RGM) form colonies on solid agar within 7 days from subculture, although sometimes primary cultures may take up to 2 weeks to grow. ${ }^{1}$ RGM skin and soft tissue infections may complicate cosmetic surgical procedures. ${ }^{2,3}$

Cosmetic surgical site infections due to RGM have been documented since $1976 .{ }^{2}$ American Board of Cosmetic Surgery defines cosmetic surgery as any procedure which enhances patient's appearance by improving aesthetic appeal, symmetry and proportion. Varieties of procedures fall into this broad cat- egory achieved by surgery, laser therapy mesotherapy and chemical agents (hydrocolloid fillers and botulinum toxin). Seeking medical care outside one's country of residence has been referred to as medical tourism. ${ }^{4}$ Due to ease of access and low costs in certain Asian and Central American countries, there has been a rise in cases of such surgeries and infections following procedures have been reported. $^{5-7}$ It is an expanding global multi-bil-

Table 1. Review of selected cases in literature. Features, treatment and outcomes of M.abscessus surgical site infections associated with medical tourism.

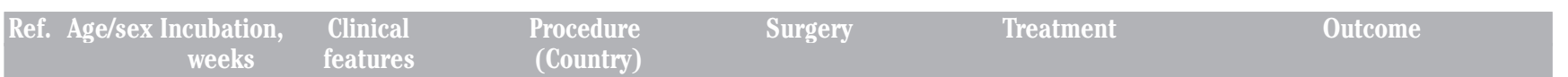

$7 \quad 38 / F \quad 2 \quad$ Erythema, painful Abdominoplasty, back Debridement bullae, draining wounds liposuction (DR)

\section{Amikacin +} cefoxitin, 3 wks; linezolid, 3 wks; clarithromycin, 6 months

\begin{tabular}{|c|c|c|c|c|c|c|c|}
\hline 7 & $19 / F$ & 10 & Subcutaneous abscesses & $\begin{array}{l}\text { Abdominoplasty } \\
\text { (DR) }\end{array}$ & Debridement & Clarithromycin for 2 mths & $\begin{array}{l}\text { Complete resolution of lesions } \\
\text { without recurrence }\end{array}$ \\
\hline 7 & $44 / F$ & 6 & $\begin{array}{l}\text { Draining wounds } \\
\qquad a b c\end{array}$ & $\begin{array}{c}\text { Abdominoplasty, } \\
\text { bdominal liposuction (DR) }\end{array}$ & Debridement & $\begin{array}{l}\text { Clarithromycin for } \\
6 \text { mths }\end{array}$ & $\begin{array}{l}\text { Complete resolution of lesions } \\
\text { without recurrence }\end{array}$ \\
\hline 7 & $26 / F$ & 4 & $\begin{array}{l}\text { Pustules, draining } \\
\text { wounds, erythema }\end{array}$ & $\begin{array}{l}\text { Abdominoplasty, } \\
\text { breast reduction (DR) }\end{array}$ & Debridement & $\begin{array}{l}\text { Cefoxitin and clarithromycin } \\
\text { for } 1 \mathrm{mnt} \text {; clarithromycin } \\
\text { for } 8 \mathrm{mths}\end{array}$ & $\begin{array}{l}\text { Complete resolution } \\
\text { of lesions without recurrence }\end{array}$ \\
\hline 7 & $35 / F$ & 3 & $\begin{array}{c}\text { Fever, } \\
\text { draining wounds }\end{array}$ & $\begin{array}{l}\text { Abdominoplasty, } \\
\text { breast reduction }\end{array}$ & $\begin{array}{l}\text { Debridement } \\
\text { (DR) }\end{array}$ & $\begin{array}{l}\text { Imipenem for } \\
3 \text { days; amikacin and cefoxitin } \\
\text { for } 6 \text { wks; clarithromycin } \\
\text { for } 12 \text { mths }\end{array}$ & $\begin{array}{l}\text { Complete resolution of } \\
\text { lesions without recurrence }\end{array}$ \\
\hline 7 & $22 / F$ & 18 & Painful mass & $\begin{array}{c}\text { Abdominoplasty, } \\
\text { breast elevation (DR) }\end{array}$ & Debridement & $\begin{array}{c}\text { Amikacin for } 7 \text { wks; } \\
\text { imipenem for } 1 \text { wk and cefoxitin } \\
\text { for } 6 \text { wks; clarithromycin } \\
\text { for } 8 \text { mths }\end{array}$ & $\begin{array}{l}\text { Complete resolution } \\
\text { of lesions without recurrence }\end{array}$ \\
\hline 7 & $58 / \mathrm{F}$ & 8 & $\begin{array}{l}\text { Erythema, pain } \\
\text { abc }\end{array}$ & $\begin{array}{l}\text { Abdominoplasty, } \\
\text { bdominal liposuction (DR) }\end{array}$ & Debridement & $\begin{array}{c}\text { Levofloxacin } 5 \text { days; } \\
\text { ciprofloxacin } \\
2 \text { wks, clarithromycin } 4 \text { mths }\end{array}$ & $\begin{array}{l}\text { Complete resolution } \\
\text { of lesions without recurrence }\end{array}$ \\
\hline 7 & $45 / F$ & 12 & $\begin{array}{l}\text { Fever, } \\
\text { draining } \\
\text { wounds }\end{array}$ & $\begin{array}{l}\text { bdominoplasty, upper back } \\
\text { liposuction (DR) }\end{array}$ & Debridement & $\begin{array}{l}\text { Azithromycin } 21 \text { months, } \\
\text { amikacin } 11 \text { mths, } \\
\text { cefoxitin } 3 \text { wks, imipenem } \\
5 \text { wks }\end{array}$ & Not improved at time of report \\
\hline
\end{tabular}

\section{9 cases Variable Multi-site Breast augmentation, presentation liposuction, abdominoplasty}

\begin{tabular}{|c|c|c|c|c|c|c|c|}
\hline 8 & 19 cases & Variable & $\begin{array}{c}\text { Multi-site } \\
\text { presentation }\end{array}$ & $\begin{array}{l}\text { Breast augmentation, } \\
\text { liposuction, abdominoplas }\end{array}$ & 14 surgery & $\begin{array}{l}1 \text { intravenous antimicrobials; } \\
5 \text { managed as out patients }\end{array}$ & Nil deaths \\
\hline 9 & $46 / F$ & 12 & $\begin{array}{l}\text { Erythema, induration, } \\
\text { discharging sinuses }\end{array}$ & $\begin{array}{cc}\text { n, } & \text { Abdominoplasty, } \\
\text { s } & \text { abdominal } \\
\text { liposuction (DR) }\end{array}$ & Debridement & $\begin{array}{c}\text { Amikacin, } \\
\text { cefoxitin and imipenem } \\
\text { followed by azithromycin }\end{array}$ & Recurrent mild transient erythema \\
\hline 9 & $60 / \mathrm{F}$ & 12 & Fever, erythema, pain & n Abdominoplasty (DR) & Debridement & Clarithromycin for $6 \mathrm{mths}$ & $\begin{array}{l}\text { Complete resolution of lesions } \\
\text { without recurrence }\end{array}$ \\
\hline 10 & $48 / \mathrm{F}$ & 12 & $\begin{array}{l}\text { Pain, erythema, } \\
\text { discharging sinuses }\end{array}$ & $\begin{array}{l}\text { Breast augmentation } \\
\text { (China) }\end{array}$ & Debridement & $\begin{array}{l}\text { Clarithromycin and } \\
\text { moxifloxacin for } 6 \text { mths }\end{array}$ & $\begin{array}{l}\text { Complete resolution of } \\
\text { lesions without recurrence }\end{array}$ \\
\hline 11 & $52 / \mathrm{F}$ & 4 & Painful leg ulcers & $\begin{array}{c}\text { Abdominal } \\
\text { liposuction (DR) }\end{array}$ & $\begin{array}{l}\text { Conservative antibiotic } \\
\text { therapy }\end{array}$ & $\begin{array}{l}\text { Clarithromycin and } \\
\text { moxifloxacin for } 8 \text { mths }\end{array}$ & Complete resolution \\
\hline 12 & $39 / \mathrm{F}$ & 13 & Gluteal ulcer & $\begin{array}{l}\text { Breast implants D } \\
\text { and gluteal lipofilling } \\
\text { (Mexico) }\end{array}$ & $\begin{array}{l}\text { Debridement and removal } \\
\text { of implants }\end{array}$ & $\begin{array}{l}\text { Tigecycline, amikacin, } \\
\text { linezolid for } 12 \text { days, } \\
\text { then moxifloxacin } \\
\text { for } 6 \text { weeks and } \\
\text { clarithromycin } 20 \text { weeks }\end{array}$ & $\begin{array}{l}\text { Complete resolution with } \\
\text { residual scarring }\end{array}$ \\
\hline 13 & 5 cases & Variable & $\begin{array}{c}\text { Multi-site } \\
\text { presentation }\end{array}$ & As above & $\begin{array}{c}\text { Surgery + antibiotic } \\
\text { therapy }\end{array}$ & $\begin{array}{c}\text { Surgery + } \\
\text { antibiotic therapy }\end{array}$ & Complete resolution \\
\hline 14 & $45 / \mathrm{F}$ & 2 & $\begin{array}{l}\text { Papular lesions } \\
\text { on legs }\end{array}$ & $\begin{array}{l}\text { Foetal stem cell } \\
\text { transfusion }\end{array}$ & Azithromycin, & $\begin{array}{l}\text { Imipenem } \\
\text { and amikacin }\end{array}$ & Improved \\
\hline
\end{tabular}


lion dollar enterprise that is projected to continue to grow significantly in the next 5 to 10 years. ${ }^{4}$ In our experience we have noticed that most patients engaging in medical tourism do not receive appropriate pre-procedure counseling and that local government regulations are frequently sparse. ${ }^{6}$

Investigations of RGM infection outbreaks have often failed to identify a source. ${ }^{3}$ However, suboptimal infection control and inadequate local cosmetic surgical oversight systems are likely to be responsible. In particular, the use of non-sterile water to clean surgical instruments, reuse of liposuction catheters, lack of autoclaving and failure to use appropriate disinfectants have been implicated. ${ }^{7}$ Due to the diverse nature of cosmetic surgery and to maintain relevance on this particular clinical case, we performed a PubMed literature search (1985-2015) with the terms Mycobacterium abscessus, Mycobacterium bolleti, Mycobacterium masseliense, cosmetic surgical procedures, surgical site infections and medical tourism; 38 selected cases of such infection reported in the English language are described in this review. The clinical details, treatment and outcomes of these patients are summarized in Table 1. ${ }^{7-14}$

All cases involved $M$. abscessus and developed after a median incubation period of 10 weeks (IQR 4-12 weeks). The long incubation period, absence of systemic features, failure to elicit the history of cosmetic surgery abroad and initial empiric treatment as a bacterial skin and soft tissue infection often leads to delayed diagnosis. This was noted with most cases described in literature too. The reporting of $M$. abscessus infections is not mandatory in most jurisdictions. Systematic surveillance is based on voluntary reporting by clinicians. ${ }^{1,7} \mathrm{~A}$ recent report of United States CDC notifying the Dominican Republic authorities of the cases of such cosmetic surgical procedures is an crucial aspect of control and public health intervention. ${ }^{8}$ The number of $M$. abscessus related infections presenting worldwide as consequence of surgical procedures should raise concerns about an emerging syndrome.

The treatment of $M$. abscessus skin and soft tissue infections can be challenging. A combination of surgical debridement and antimicrobial chemotherapy is usually required. Surgery is important in decreasing disease burden, as pharmacotherapy is associated with significant limitations. Firstly, the length of treatment is not standardized, although prolonged therapy is often required for cure. ${ }^{15}$ Combination therapy is usually necessary to prevent emergence of resistance. ${ }^{16}$ Secondly, in vitro drug susceptibility does not reliably predict treatment response and molecular methods like detection of erm gene assists with therapeutic decision of long term macrolide therapy for treatment. ${ }^{15,17}$ Thirdly, antibiotic therapy may be further complicated by adverse drug reactions. Hearing impairment, vestibular damage and nephrotoxicity may result from amikacin use. ${ }^{1,15}$ Linezolid is associated with myelotoxicity, lactic acidosis and neuropathy. ${ }^{1,15}$ The potential for serotonin syndrome when linezolid is used in combination with selective serotonin reuptake inhibitors (SSRI) and tramadol needs to be carefully considered when planning therapy. A hypersensitivity rash associated with cefoxitin treatment also occurred in our patient. Being a non-class effect, this does not preclude the future use of other agents in this class for other infections. ${ }^{1,15}$ Complete resolution of lesions secondary to $M$. abscessus occurred in $36(94.7 \%)$ of the 38 cases described in Table 1. Although the medical prognosis appears to
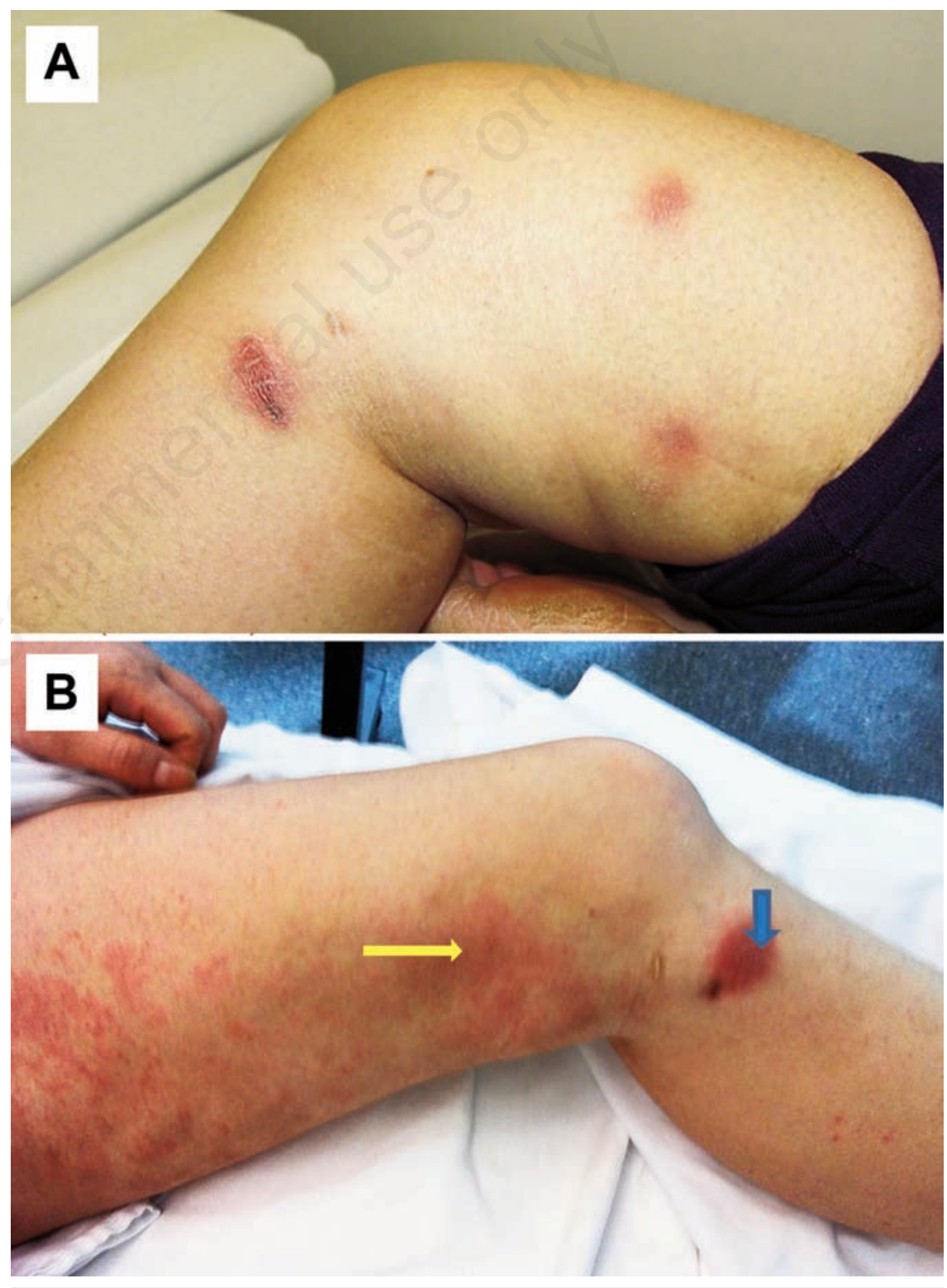

Figure 1. A) Papular lesions present on the right thigh and leg on admission; B) drug induced maculopapular skin rash (yellow arrow-from Cefoxitin) and occurrence of new nodule (blue arrow). be relatively good, the consequent cosmetic and psychological outcomes as a result of both disease and treatment may be significant.

Taxonomy of Mycobacterium abscessus has evolved to include three subspecies within its complex: M. abscessus subsp. abscessus, M. abscessus subsp. bolletii, Mycobacterium abscessus subsp. massiliense. ${ }^{17}$ For detecting differences in these subspecies isolation and amplification of the $r p o B, \sec A 1, \operatorname{sod} A, \operatorname{rec} A$, $h s p 65$ and internal transcribed spacer (ITS) region between $16 \mathrm{~S}$ and $23 \mathrm{~S}$ RRNA region have been utilised. ${ }^{18}$ Differences in the erm gene are associated with inducible clarithromycin resistance amongst the $M$. abscessus complex, suggesting that an accurate identification of the erm gene is important to predict treatment outcomes. ${ }^{19}$ While M. abscessus 
subsp. abscessus, and M. abscessus subsp. bolletii frequently demonstrate inducible macrolide resistance, Mycobacterium abscessus subsp. massiliense mostly remains susceptible. ${ }^{20}$

The treatment of mycobacterial infections may be associated with transient deterioration following a period of improvement, a condition termed a paradoxical reaction. ${ }^{17}$ Among immune-competent patients, paradox is wellrecognized in Mycobacterium tuberculosis complex and Mycobacterium leprae infections. ${ }^{21,22}$ For NTM, paradoxical reaction has been reported in cases of Mycobacterium ulcerans skin and soft tissue infection and $M$. abscessus pulmonary disease. ${ }^{23-25}$ This patient was deemed to have developed a paradoxical reaction on the basis of multiple negative debrided tissue cultures and the prompt and substantial response to corticosteroids. To our knowledge, this is the first reported case of the occurrence of paradoxical reaction during the treatment of a $M$. abscessus skin and soft tissue infection. The management should begin with the exclusion of treatment failure (due to intrinsic or inducible resistance and/or poor treatment compliance) and bacterial super infection. In cases of $M$. ulcerans infections, prednisone 0.5 to $1 \mathrm{mg} / \mathrm{kg} /$ day for 4 to 6 weeks has been well-tolerated and associated with marked clinical improvement within days to weeks. ${ }^{24}$ Furthermore, prednisone may obviate the need for further surgical debridement. ${ }^{24}$

\section{Conclusions}

As medical tourism expands, the incidence of $M$. abscessus cosmetic surgical site infections is likely to rise. $M$. abscessus and other NTM should be included in the differential diagnosis of skin and soft tissue infections with features atypical for a bacterial etiology. The paradoxical reaction should be considered with recurrence of symptoms and signs during treatment despite effective therapy.

\section{References}

1. De Groote MA, Huitt G. Infections due to rapidly growing mycobacteria. Clin Infect Dis 2006;42:1756-63.

2. Clegg HW, Foster MT, Sanders WE Jr, Baine WB. Infection due to organisms of the Mycobacterium fortuitum complex after augmentation mammoplasty: clinical and epidemiologic features. $\mathrm{J}$ Infect Dis 1983;147:427-33.
3. Torres J, Murillo J, Bofill L, et al. Rapidly growing mycobacterial infection following liposuction and liposculpture. Caracas, Venezuela, 1996-1998. MMWR 1998;47:1065-7.

4. Lee CV, Balaban V. Center for Disease Control and Prevention. Yellow Book Chapter 2: The pre-travel consultation counselling and advice for travellers Medical tourism, 2012. Available from: http://wwwnc.cdc.gov/travel/yellowbook/20 $12 / \mathrm{c} \mathrm{h}$ a p t e r - 2 - th e - p r e - travelconsultation/medical-tourism. Accessed on: October 2015.

5. Estivariz C. Brief report: nontuberculous mycobacterial infections after cosmetic surgery - Santo Domingo, Dominican Republic, 2003-2004. MMWR 2004;53:509.

6. Chavada R, Hui SH, Nagendra V. Medical tourism raises questions that highlight the need for care and caution. Med J Aust 2015;203:137.

7. Furuya EY, Paez A, Srinivasan A, et al. Outbreak of Mycobacterium abscessus wound infections among lipotourists from the United States who underwent abdominoplasty in the Dominical Republic. Clin Infect Dis 2008;46:1181-8.

8. Schnabel D, Gaines J, Nguyen DB, et al. Notes from the field: rapidly growing nontuberculous Mycobacterium wound infections among medical tourists undergoing cosmetic surgeries in the Dominican Republic--multiple states, March 2013February 2014. MMWR 2014;63:201-2.

9. Newman MI, Camberos AE, Ascherman J. Mycobacterium abscessus outbreak in US patients linked to offshore surgicenter. Ann Plast Surg 2005;55:107-10.

10. Feldman EM, Ellsworth W, Yuksel E, Allen S. Mycobacterium abscessus infection after breast augmentation: a case of contaminated implants? J Plast Reconstr Aesthet Surg 2009;62:e330-2.

11. Zosso C, Lienhard R, Siegrist HH, et al. Post liposuction infections by rapidly growing mycobacteria. Infect Dis (London, England) 2015;47:69-72.

12. Ruegg E, Cheretakis A, Modarressi A, et al. Multisite infection with Mycobacterium abscessus after replacement of breast implants and gluteal lipofilling. Case Rep Infect Dis 2015:361340.

13. Maurer F, Castelberg C, von Braun A, et al. Postsurgical wound infections due to rapidly growing mycobacteria in Swiss medical tourists following cosmetic surgery in Latin America between 2012 and 2014. Eurosurveillance 2014;19.

14. Kendall BA, Barker AP, Hadley JC, et al. Disseminated mycobacterial infection after international medical tourism. Open
Forum Infect Dis 2015;2:0fv054.

15. Griffith DE, Aksamit T, Brown-Elliot BA, et al. An official ATS/IDSA statement: Diagnosis, treatment and prevention of nontuberculous mycobacterial diseases. Am J Respir Crit Care Med 2007;175:367416.

16. Vemulapalli RK, Cantey JR, Steed LL, et al. Emergence of resistance to clarithromycin during treatment of disseminated cutaneous M.chelonae infection: case report and literature review. J Infect 2001;43:1638.

17. Nash KA, Brown-Elliott BA, Wallace RJ Jr. A novel gene, erm(41), confers inducible macrolide resistance to clinical isolates of Mycobacterium abscessus but is absent from Mycobacterium chelonae. Antimicrob Agents Chemother 2009;53:1367-76.

18. Sassi M, Drancourt M. Genome analysis reveals three genomospecies in Mycobacterium abscessus. BMC Genomics 2014;15:359.

19. Nakanaga K, Sekizuka T, Fukano H, et al. Discrimination of Mycobacterium abscessus subsp. massiliense from Mycobacterium abscessus subsp. abscessus in clinical isolates by multiplex PCR. J Clin Microbiol 2014;52:251-9.

20. Brown-Elliott BA, Vasireddy S, Vasireddy $\mathrm{R}$, et al. Utility of sequencing the erm(41) gene in isolates of Mycobacterium abscessus subsp. abscessus with low and intermediate clarithromycin MICs. J Clin Microbiol 2015;53:1211-5.

21. Chloremis CD, Padiatellis C, Zoumboulakis D, Yannakos D. Transitory exacerbation of fever and roentgenographic findings during treatment of tuberculosis in children. Am Rev Tuberc 1955;72:527-36.

22. Cheng SL, Wang HC, Yang PC. Paradoxical response during antituberculous treatment in HIV-negative patients with pulmonary tuberculosis. Int $\mathrm{J}$ Tuberc Lung Dis 2007;11:1290-5.

23. O'Brien DP, Robson ME, Callan PP, McDonald AH. Paradoxical immune-mediated reactions to Mycobacterium ulcerans during antibiotic treatment: a result of treatment success, not failure. Med J Aust 2009;191:564-6

24. Friedman ND, McDonald AH, Robson ME, 0'Brien DP. Corticosteroid use for paradoxical reactions during antibiotic treatment for Mycobacterium ulcerans. PLoS Negl Trop Dis 2012;6:1-3.

25. Yano S, Kobayashi K, Kato $\mathrm{K}$, et al. Paradoxical worsening of pulmonary Mycobacterium abscessus. Respir Med 2007;101:868-70. 